\title{
El motín de Madrid de 1766 en los Archivos Diplomáticos de París
}

\author{
JoSÉ A. FERRER BENIMELI \\ Universidad de Zaragoza
}

Las nuevas tendencias historiográficas, más preocupadas por cuestiones socio-agrarias y de subsistencia, han hecho que los motines contra Esquilache hayan cobrado nueva actualidad y que la bibliografía empiece a ser abundante y mejor documentada ${ }^{1}$. Sin embargo todavía si-

1 Anes G., «Antecedentes próximos del motín contra Esquilache», Moneda y Crédito, 128 (1974) 219-224; Cadenas y Vicent, Vicente de, «Concesión de veintiuna hidalguías a otros tantos sujetos que se distinguieron en la represión del tumulto acaecido en Zaragoza en 1766», Hidalguía, n. ${ }^{\circ} 15$ (1956) 156-164; Corona, C., «El motín de Zaragoza del 6 de abril de 1766», Zaragoza, 14 (1961) 197-228; Corona, C., «Los premios de Carlos III a los Broqueleros de Zaragoza por su actuación en los sucesos de abril de 1766. Los alcaldes perpetuos del Arrabal», en Miscelánea ofrecida al Ilmo. Sr. Dr. José M. ${ }^{a}$ Lacarra y de Miguel, Zaragoza, Universidad, 1968, págs. 153-173.; Corona, C., «El poder real y los motines de 1766», en Homenaje al Dr. Canellas, Zaragoza, Universidad, 1969, págs. 259-274; Corona, C., «Los sucesos ocurridos desde marzo a mayo de 1766 en Tobarra, Oviedo, Totana, Quesada y Lietor», Cuadernos de Investigación [Logroño] III (1977) 99-120, Corona, C., Los motines de 1766 en las provincias vascas. La Machinada, Zaragoza, Universidad, 1985; Corona, C., «Los motines en la Gobernación de Alicante en abril de 1766», Anales de Literatura Española [Alicante], 2 (1983) 103-132; Corona, C., «Los sucesos de Palencia en abril de 1766», Cuadernos de Investigación Histórica [Madrid], 3 (1979) 35-54; Corona, C., «Los sucesos en Badajoz, el 7 de abril, y en Baza, el 25 de mayo de 1766», en Homenaje al Dr. D. Eugenio Frutos, Zaragoza, Universidad, 1977, págs 93-107; Corona, C., «Los sucesos de Sevilla y Jaén en Abril de 1766», 
guen siendo infrautilizados los fondos diplomáticos procedentes de las cancillerías que tenían embajador en España en la primavera de 1766.

Precisamente en uno de éstos, el correspondiente al Quai d'Orsay o Archivos Diplomáticos de París, se encuentra una nueva versión de lo sucedido en Madrid el 23 de marzo de 1766, escrita al calor de los acontecimientos por el embajador francés en España, marqués d'Os-

Hispania, n. ${ }^{\circ} 137$ (1977) 541-568; Corona Marzal, Carmen, Documentos del reinado de Carlos III relativos a los sucesos de Lorca de 1766, Tesis de Licenciatura inédita (Mayo 1974) 275 fols.; Egido, T., «Oposición radical a Carlos III y expulsión de los jesuitas», Boletín de la Real Academia de la Historia, CLXXIV (III, 1977) 529-545; Egido, T., «Motines de España y proceso contra los jesuitas. La pesquisa reservada de 1766», Estudio Agustiniano XI (II 1976) 219-228; Egido, T., «Madrid 1766: «Motines de Corte» y oposición al Gobierno», Cuadernos de Investigación Histórica [Madrid] 3 (1979) 125-153; Eguía, C., «Un supuesto cómplice del motín de Esquilache. El abate montañés Gándara», Boletín Biblioteca Menéndez y Pelayo (julio-sep. 1934); Eguia, C., Los jesuitas y el motín de Esquilache, Madrid, C. S. I. C., 1947; Ferrer Benimeli, J.A., «El motín de Esquilache y sus consecuencias según la correspondencia diplomática francesa», Archivum Historicum Societatis Iesu [Roma],LIII, 105 (Ian.-Iun. 1984) 193-219; Ferrer Benimeli, J. A., «D. Ramón Pignatelli y el motín de Esquilache. Una nueva versión del motín de Zaragoza», en Actas del I Coloquio sobre la Ilustración Aragonesa, Zaragoza, D. G. A., 1986, (en prensa); Frias, L., «Los jesuitas y el motín de Esquilache en la Historia de España por Rafael Altamira», Razón y Fe, XXIX (1911) 161-178, 277-287; Gurruchaga, I., «La machinada del año 1766 en Azpeitia. Sus causas y desarrollo», Yakintza (San Sebastián) 5'go zenbakia 1933'ko. Agor-Urila; Jiménez Monteserin, M., «Los motines de subsistencias de la primavera de 1766 y sus repercusiones en la ciudad de Cuenca", Cuenca, n. ${ }^{\circ} 11$ y $12\left(1 .^{\circ}\right.$ y $2 .^{\circ}$ semestre 1977); Jiménez Soler, «El motín de los broqueleros», Aragón [Zaragoza] X, n. ${ }^{\circ} 106$ (jul. 1934) 123-126; Latre, Thomás Sebastián de, Relación Individual y verídica del suceso acontecido en la Ciudad de Zaragoza el día 6 de abril de 1766 ..., Zaragoza, 1766, Impta. del Rey N. S. Facs., Zaragoza, Librería General, 1986; Melón Ruiz de Gordejuela, A., «El motín de Esquilache en Zaragoza (1766)», Atheneum, IV (primer trim. 1924), 17-34; Navarro, J., Hace doscientos años. Estado actual de los problemas históricos del «motín de Esquilache», Madrid, Inst. Estudios Madrileños, 1966; Nipho, F. M., Relación verdadera y circunstanciada de todo lo acaecido en la Ciudad de Zaragoza desde $1 .^{\circ}$ de abril de este año de 1766 hasta el 15 del mismo, Madrid, Miguel Escrivano, 1766; Olaechea, R., «Contribución al estudio del motín contra Esquilache, 1766» en Estudios en Homenaje al Dr. Frutos, Zaragoza, Universidad, 1977, págs. 213-374; Olaechea, R., «Resonancias del motín contra Esquilache en Córdoba (1766)», Cuadernos de Investigación [Logroño], IV (1978) 75-124; Idem en Actas del I Congreso de Historia de Andalucía, Córdoba, 1978, vol. IV, págs. 81-112; Otazu, A. de, «La represión de la matxinada de 1766 ", en La Burguesía revolucionaria vasca a fines del siglo XVIII, San Sebastián, Ed. Txertoa, 1982, págs. 17-103; Palop, J. M., Hambre y luchas antifeudales: las crisis de subsistencias en Valencia (s. XVIII), Madrid, 1977; Peiró Arroyo, A., «La crisis de 1763-66 en Zaragoza y el Motín del pan», Cuadernos Aragoneses de Economía [Zaragoza], n. ${ }^{\circ} 6$ (1981-82) 239-250; Rodríguez, L., «El motín de Esquilache y las crisis del Antiguo Régimen», Revista de Occidente [Madrid], 107 (1972) 200-247; Rodríguez, L., «Los motines del 1776 en pro- 
sun, y que fue remitida al duque de Choiseul ${ }^{2}$ desde Aranjuez, el 27 de marzo, en una amplia relación de trece folios que lleva por título Detalle de la Revuelta Acaecida en Madrid el 23 [marzo 1766], y que dice así:

Un suceso bien extraordinario da lugar a la expedición que tengo el honor de haceros hoy. Hubo, señor, una revuelta en Madrid comenzada el 23 hacia la tarde por el pueblo más bajo, pero verosímilmente fomentada y sostenida por los sacerdotes, por los monjes y por gentes de una especie más considerable que el bajo pueblo o de simples artesanos. Esta revuelta pareció tener por motivo lo que sigue.

Los españoles tenían la costumbre de usar sus sombreros con las alas caídas, y capas muy amplias y largas de un paño negruzco; de ir por las calles, paseos y a los espectáculos públicos de día y de noche, ocultos o mejor dicho enmascarados por esta forma de vestir, de forma que no podían ser reconocidos y distinguidos unos de otros. Es fácil de comprender los abusos y la impunidad que esta mascarada continua favorecía. Su Majestad Católica ordenó en consecuencia que nadie pudiera aparecer en público sin el sombrero compuesto, que todos los oficiales, las personas de la judicatura, todos los plumistas y aduaneros así como las gentes de su casa ya no llevasen capas negruzcas, y que los demás las llevasen recortadas hasta el punto de dejar ver la mitad de la pierna. Por otro lado el Marqués de Grimaldi había iluminado la Villa de Madrid, mejor que cualquier otra capital de Europa, por medio de cerca de cinco mil faroles, y había gastado para ello más de doscientos cincuenca mil francos. Sucedió, señor, que el 23, a las cuatro de la tarde, algunos españoles se mostraron en las calles de Madrid con los sombreros bajos y las capas prohibidas, y resistieron a la guardia que les quiso detener.

El número de infractores aumentó poco a poco. Hacia las seis fueron a insultar la casa del Gobernador de la Corte y la del marqués de Esquilache; rompieron los cristales de una y otra. Finalmente a las siete todos los barrios de la villa fueron inundados por treinta, cuarenta y hasta cien bribones que gritaban Viva el Rey Carlos III y Muera Esquilache. Rompieron todos los faroles y obligaron a los que se encontraban a bajar las alas de sus sombreros. Detenían las carrozas y forzaban a los dueños y domésticos a la misma formalidad. Decían y hacían mil insolencias. Una cuadrilla de más de mil

vincias», Revista de Occidente, 122 (1973) 183-207; Rodríguez, L., "The Spanish Riots of 1766», Past and Present, 59 (mayo 1973) 117-143; Ruiz, P., «Los motines de 1766 y los inicios de la crisis del Antiguo Régimen, en Estudios sobre la revolución burguesa en España, Madrid, 1979, págs. 29-112; Soubeyroux, J., «Le motin de Esquilache et le peuple de Madrid», Cahiers du monde Hispanique et lusobrésilien, Caravelle, 31 (1978) 59-79; Vilar, P., «El motín de Esquilache y las crisis del antiguo régimen», Revista de Occidente, 36 (1972) 233-246. A estas obras habría que añadir otros trabajos más generales en los que, tratando otras cuestiones especialmente económicas y sociales, se aborda de forma indirecta el tema de los motines contra Esquilache.

2 Choiseul (Etienne-François, duque de), [1719-1785], ministro de Asuntos Exteriores bajo Luis XV, de 1758 a 1770 .

3 Archives Diplomatiques de Paris, Correspondance Politique, Espagne, vol. 545 (1766), fols. 227-240. Aranjuez, 27 de marzo de 1766 (Détail de revolte arrivée à Madrid le 23). En lo sucesivo A.D.P. 545. 
rodearon constantemente la casa del marqués de Esquilache, que fue destrozada a pedradas. El Ministro, felizmente para él, se encontraba en Palacio. Su mujer se refugió a tiempo en casa del Embajador de Holanda, y llegaron tropas para custodiar su casa. Hubo tiros y un español fue muerto delante de la puerta.

La guarnición de Madrid, que consistía en dos batallones, uno de Guardias Españoles y otro de Guardias Walonas, y mil Inválidos y seiscientos Guardias de Corps, tomó también pronto las armas. Los Inválidos ocuparon según costumbre varios cuerpos de guardia en las Plazas y calles principales; pero estos diferentes puestos en su mayoría tomaron el partido de encerrarse en los cuerpos de guardia sin ofrecer ninguna resistencia; y los que no lo hicieron fueron forzados, desarmados y obligados a retirarse después de haber disparado algunos tiros de fusil. En total murieron una docena de sublevados. Estos últimos incluso osaron insultar el cuartel de los Inválidos, y faltó poco para que se hicieran dueños por sorpresa. Los batallones de Guardias y los Guardias de Corps volvieron inmediatamente al Palacio real y detuvieron al pueblo que se dirigía a él en masa gritando sin cesar ; Viva el Rey, Viva España, muera Esquilache, mueran los italianos! Hacia las nueve y media se destacaron del Palacio algunas patrullas de Infantería y Caballería que recorrieron plazas y calles. Con esta maniobra se disipó poco a poco la multitud, de forma que a las once solamente quedaban pequeños grupos por aquí y por allá, y a medianoche la tranquilidad estaba ya restablecida en toda la ciudad. No obstante las tropas pasaron la noche en armas en la Plaza del Palacio del Rey, y Su Majestad Católica encargó al Sr. Orelly mandarles y vigilar el día siguiente por la seguridad pública. Se dieron órdenes a las tropas que se encontraban más próximas para que entraran urgentemente en Madrid. Pero el número de estas tropas se reduce a quinientos hombres de infantería que estaban en Segovia, ciudad distante diez y seis leguas de la Capital, y seiscientos carabineros que están un poco más alejados, a un regimiento de Caballería todavía más alejado, y a doscientos cincuenta voluntarios de a pie, situados a cuatro leguas de la capital.

El 24, a las siete de la mañana, se sublevó de nuevo un mayor número que a la víspera, y más de treinta mil entre hombres y mujeres marcharon a Palacio gritando -Viva el Rey, muera Esquilache, que se baje el precio del pan y del aceite, que se quite la Junta de Abastos; que se revoque la prohibición de las capas largas y de los sombreros gachos! Entonces el Sr. Orelly, que había protegido las avenidas del Palacio con piquetes de Infantería y Guardias de Corps, dijo al Rey de España en una conferencia secreta que tenía dos partidos que tomar: el de rigor o el de la clemencia; que si su Majestad Católica optaba por el primero, él respondía de disolver al pueblo. Pero con mucha efusión de sangre. Que si el Rey de España prefería la clemencia, él podía asegurarle que los sediciosos no iban contra su persona.

Su majestad Católica le respondió en primer lugar que tomara el partido que creyera más sensato y conveniente. Pero S. M. testimonió enseguida su repugnancia a derramar la sangre de sus súbditos. En consecuencia el Sr. Orelly solamente intentó contener a los amotinados con buenas palabras, y supo ganarse su confianza hasta el punto de poder mezclarse con ellos, ir y venir a través de este populacho inmenso sin encontrar la menor ofensa.

Las cosas se mantuvieron así en los puestos en los que había Guardias Españoles y Guardias de Corps. Pero los que ocupaban los Guardias Walones fueron atacados a pedradas y hostigados de tal forma que un piquete se vio obligado a disparar y mató a tres mujeres y dos hombres. Este accidente animó de tal forma al pueblo que se abalanzó sobre las bayonetas de los Walones. Las mujeres con más intrepidez y furor que los hombres. Esto ocurrió en uno de los puestos de la Corte del Palacio, y poco tiempo después un piquete del mismo cuerpo que estaba más adelante, en la entrada de la Plaza Mayor de Madrid fue obligado a retirarse, y se tomó el partido de hacer entrar a 
todos los Walones en la Corte del Palacio y de sacar las tropas españolas a la calle, para quitar a los sediciosos el motivo de furor que les daba la presencia de los Walones y de los demás extranjeros.

La situación se mantuvo así hasta las once, repitiendo el pueblo sin cesar las mismas peticiones a las que añadió la de que el Rey sacara los Walones de Madrid. Entonces Su Majestad Católica hizo publicar y fijar por medio de carteles que si el pueblo entraba en su deber concedería una disminución sobre el pan y el aceite, y que conociendo los deseos de su pueblo sobre los otros temas, tomaría a este respecto las medidas que su bondad y prudencia le sugeriría. Los amotinados, en lugar de calmarse, arrancaron los carteles y redoblaron sus gritos. Entre el mediodía y la una el Rey de España envió al duque de Medinaceli, su escudero mayor, y al duque de Arcos, su capitán de Guardias para toda la nación, para exhortar al pueblo a retirarse y prometerle de parte de Su Majestad Católica una disminución más considerable sobre el precio del pan y del aceite, y que se quitaría la Junta de Abastos.

Estos señores no tuvieron más éxito que los bandos y regresaron hacia las dos. Él Rey de España les envió una segunda vez para anunciar al pueblo que si no entraba en su deber Su Majestad Católica elegiría otra capital. Esta segunda diligencia fue tan inútil como la primera. El pueblo, por el contrario, todavía se hizo más insolente. Poco después, es decir, a las tres de la tarde, el Rey de España hizo salir cuatro religiosos franciscanos, llamados por su confesor, que es de esta orden. Un gran crucifijo iba delante de ellos, y fueron a exhortar al pueblo a entrar en su deber y anunciarle que el Rey dimitía de las finanzas al marqués de Esquilache, y que en su lugar había nombrado a Don Miguel Muzquiz (es el primer conocido de las finanzas y secretario del Consejo de Guerra; un hombre de mérito y capacidad);que Su Majestad Católica suprimía la Junta de Abastos; que concedía la disminución pedida sobre el pan y el aceite; que revocaba la prohibición de las capas y sombreros. Finalmente, que ya no habría más Walones en Madrid.

El Rey de España, señor, se determinó a ceder sobre todos estos puntos porque carecía de tropa y su palacio podía ser forzado sobre todo durante la noche; y porque los amotinados hablaban abiertamente de saquear y de quemar la ciudad. Finalmente porque había razones para temer que este pueblo feroz, cegado y furioso, llegara a los mayores excesos. No obstante, los sediciosos no se contentaron con la palabra de los monjes. Se obstinaron en querer ver a su Rey, de suerte que hacia las cinco, después de haber protegido el interior del palacio con tropas y haber hecho retirar la Infantería que guardaba el principal patio, el Rey de España apareció en un gran balcón que existe en el centro del palacio. El pueblo entró en tropel hasta debajo del balcón (los monjes y el crucifijo a la cabeza) gritando ¡Viva el Rey!, arrojando sus sombreros al aire y haciendo un alboroto increíble en señal de obediencia y de alegría. Entonces uno de los monjes impuso silencio con el sonido de una campanilla, y leyó en voz alta las condiciones que Su Majestad Católica concedía a los sediciosos. Fue interrumpido a menudo por aclamaciones y por gritos de ¡Viva el Rey!. Una vez concluida la lectura, el monarca hizo señal de que ratificaba lo que el monje acababa de publicar, y el pueblo comenzó a retirarse.

Hay que destacar, señor, que sólo la canalla entró en el patio del palacio, y que los sacerdotes, monjes y gentes distinguidas entre la burguesía que había sostenido la sedición no se hicieron visibles. Finalmente, habiendo comenzado a restablecerse la calma, apareció una procesión o rosario conducido por dominicos con un total de más de cuatro mil personas. Llevaban una gran estatua de la Virgen. Este rosario se colocó bajo las ventanas del palacio, se cantaron oraciones y se gritaron vivas al Rey alternativamente. Esto duró hasta la entrada de la noche. El pueblo se retiró poco a poco y a las diez de la noche todo estaba tranquilo. 
Volví al palacio por la mañana hacia las nueve y media pasando, no obstante, por fuera de la ciudad. Ni mi hotel, ni mi persona, ni mi carroza han experimentado ningún insulto en estas dos primeras jornadas. Al contrario he oído muchos ¡Viva España y Francia! Por otra parte personalmente soy amado del pueblo y de la nación.

Estando ya todo pacificado, señor, el Rey de España ha juzgado oportuno partir a las dos de la madrugada hacia Aranjuez en la noche del 24 al 25 con la Reina su madre y toda la familia real. Las disposiciones de esta marcha se tuvieron tan secretas que yo no fui informado de ellas hasta el 25 a las siete de la mañana. A las ocho salí con un secretario y tres domésticos. He dado orden a toda mi casa de seguirme tan pronto como les sea posible. Pero hasta ahora no han llegado ni domésticos, ni bagaje porque el pueblo, después de la marcha nocturna del Rey de España para Aranjuez, se ha amotinado de nuevo con el pretexto de que el soberano dudaba de su fidelidad, y para comprometerle a regresar a Madrid - decían ellos - los sediciosos se han apoderado de casi todas las armas de los Invalidos y de algunas otras que han encontrado en la ciudad. Se han hecho también dueños de un almacen de pólvora y han ocupado todas las puertas de la ciudad, el puente de Toledo y el vado que conduce al camino de Aranjuez, y no han permitido a ningún coche ni a nadie tomar esta ruta. Ni siquiera han respetado la comitiva de Su Majestad Católica. Además han molestado a varias personas en las calles y hecho mucho ruido toda la jornada.

Al llegar a Aranjuez he encontrado al Rey de España y a toda su familia real en buena salud, y a este monarca ocupado en dictar disposiciones para impedir que los sediciosos vengan a él, si contra toda apariencia se atrevían a hacerlo. Los Guardias de Corps y el batallón de Guardias Walonas que estaban en Madrid han llegado aquí; los carabineros también han venido. Pero estas precauciones serán seguramente excesivas porque según las noticias de ayer 26 los tribunales de Madrid comenzaban a recuperar la autoridad, y los sediciosos les habían entregado en parte las armas de las que se habían apoderado. También comenzaban a permitir a los que querían acudir a Aranjuez el poder hacerlo.

Creo, señor, que se podrían atribuir estos pasos de sumisión al efecto del consejo que me tomé la libertad de dar a Su Majestad Católica, y que ha aprobado. Este consejo fue hacer insinuar al Monseñor arzobispo de Toledo que llamara al clero de Madrid; a los superiores de órdenes que obraran de la misma forma respecto a los monjes; a los cinco cuerpos de comerciantes llamados Gremios de reunirse con todos los que dependen de ellos; a todos los Tribunales, Juntas, Contadurías de reunirse igualmente, a fin de que los jefes de estos diferentes cuerpos les exhortasen de parte del Rey de España no solamente a no mezclarse en la revuelta, sino, al contrario, a tomar medidas vigorosas y eficaces para detener la insolencia del pueblo, y prevenir los excesos y desórdenes que de ello pudieran resultar; y para hacerles volver enteramente a la obediencia.

Esta manera de proceder, señor, me ha parecido conveniente, primero, porque con ella se proporciona a los individuos de estos diferentes cuerpos que hubieran podido estar mezclados en la sedición un medio honesto de apartarse, y la facilidad de ocultar su falta. Segundo, porque todas las veces que la parte más sana de los habitantes de Madrid pueda presentarse a los ojos del Rey de España como inocente, y pedirle en consecuencia gracia para el bajo pueblo, este Príncipe se encontrará en situación de perdonar, o al menos de restringir el castigo a un muy pequeño número de individuos, sin comprometerse su dignidad y su poder, y es lo que yo creo que Su Majestad Católica podría desear más después de la escandalosa revolución que acaba de experimentar.

El Marqués de Esquilache, su mujer, uno de sus hijos y uno de sus primos que habían acompañado al Rey a Aranjuez salieron la noche del 25 al 26 para llegar lo más rápida y secretamente posible a Cartagena, de donde pasarán inmediatamente a Nápoles en un barco del Rey de España. Este ex-ministro sacrificado a las circunstancias, 
y principalmente al odio del clero, ha sido el primero en solicitar su partida, sea con la esperanza de que esta circunstancia traería la tranquilidad pública, sea por el temor demasiado bien fundado de que su vida no estaría ya en seguridad en este reino.

Os parecerá, señor, que quizás he diferido un poco en expediros un correo, sobre todo no habiéndoos escrito por el ordinario del 23. No tenía a nadie que poder enviaros y el señor Marqués de Grimaldi ha estado hasta el presente en la misma situación. Por otra parte he querido ver el giro que tomaban las cosas. He preguntado a Su Majestad Católica si quería escribir al Rey o encargarme sus órdenes cerca de $\mathrm{Su}$ Majestad. El Rey de España me ha respondido que no tenía nada que mandar al Rey su primo de momento, que contaba esencialmente con su amistad y sus fuerzas, y que recurriría con confianza si el caso lo exigía. Pero que esto sólo sería en caso extremo.

No debo omitir, señor, informaros que el Rey de España hace venir algunos regimientos de Infantería y Caballería hacia la Capital a fin de estar dentro de quince días como máximo en estado de someter esta ciudad por la fuerza si ella no implora su clemencia como todo parece anunciarlo desde hace veinticuatro horas.

Tengo el honor de quedar con tanta adhesión como respeto,

Señor, Vuestro humilde y muy obediente servidor

OSSUN

P.S. Su Majestad Católica, señor, recibió el 25 a las siete de la tarde una carta abierta del Gobernador del Consejo de Castilla que había sido leída al pueblo, y que los sediciosos hicieron llegar a Aranjuez por uno de ellos. Esta carta decía en substancia que el pueblo de Madrid estaba fiel y respetuosamente unido al Rey. Pero que no abandonaría las armas si Su Majestad Católica no les daba una prueba de su confianza volviendo lo antes posible a Madrid. El Rey de España les respondió por uno de sus secretarios de Estado que él amaba a su pueblo y que no dudaba de su fidelidad; que su intención no era cambiar su capital, pero que no volvería hasta que todo hubiera entrado en orden y en la tranquilidad ordinarias. La respuesta del Rey fue leída al pueblo el 26 por la mañana por medio del Secretario del Consejo de Castilla y en presencia de todo el Consejo reunido. El pueblo satisfecho remitió al instante sus armas, y antes de concluir el día el orden había sido restablecido y todo pacificado.

Añado aquí, señor, una carta de la Señora Princesa de Asturias para Su Majestad.

\section{Complot clerical-burgués}

De la versión que el embajador francés hace de la revuelta de Madrid, a la que llega a calificar de escandalosa revolución ${ }^{4}$, se podrían sacar varias conclusiones. La primera y más llamativa es el protagonismo del clero, en contra de otras opiniones recogidas en su día por auto-

4 Los diversos calificativos usados por Ossun son de revuelta, motín, sedición y revolución. 
res como Von Pastor, Danvila o Rousseau ${ }^{5}$. Pues ya desde las primeras líneas hay una alusión directa a los presuntos autores del que la historiografía tradicional viene en llamar motín de Esquilache, y que el profesor Olaechea prefiere denominar motines contra Esquilache ${ }^{6}$ : «Hubo, señor, una revuelta en Madrid comenzada el 23 hacia la tarde por el pueblo más bajo, pero verosímilmente fomentada y sostenida por los sacerdotes, por los frailes y por gentes de una especie más considerable que el bajo pueblo o simples artesanos» ${ }^{7}$.

Y más adelante, cuando relata la participación de franciscanos y dominicos en un intento por calmar al pueblo que quiso ver al rey en el balcón de palacio, vuelve a insistir en la misma idea: «Hay que destacar, señor, que sólo la canalla entró en el patio del palacio, y que los sacerdotes, frailes y gentes distinguidas entre la burguesía que habían sostenido la sedición no se hicieron visibles) ${ }^{8}$.

Todavia volverá en dos ocasiones sobre la misma cuestión. La primera cuando sugiere que el arzobispo de Toledo llame al clero de Madrid, y los superiores de órdenes a sus súbditos, para exhortarles a que no se mezclaran en la revuelta, ya que así se proporcionaba a aquellos que hubieran podido estar involucrados en la sedición un medio honesto de apartarse. La otra es cuando se refiere al exilio de Esquilache y habla del «ex-ministro sacrificado a las circunstancias, y principalmente al odio del clero» ${ }^{9}$.

La actuación del clero no es considerada exclusiva ya que va unida a la de «gentes de una especie más considerable que el bajo pueblo o de simples artesanos». Es decir que desde el primer momento, al menos

5 Pastor, L. Von, Historia de los Papas en la época de la monarquía absoluta, Barcelona, Ed. G. Gili, 1937, vol. XXXVI, págs. 354-355; Danvila, M., Reinado de Carlos III, Madrid, 1891; Rousseau, F., «Expulsión des Jésuites en Espagne. Démarches de Charles III pour leur sécularisation», Revue des Questions Historiques, 75 (1904) 113-179. Aquí Ossun se adelantó a cualquier otro político, pues Du Tillot, Tanucci..., no llegan a la misma conclusión hasta fines de abril, es decir, un mes más tarde.

6 Olaechea (vid. nota 1).

7 Vid. nota 3.

8 Ibídem.

9 Ibídem. Sobre este particular vid. Ferrer Benimeli, J.., «El motín de Esquilache y sus consecuencias según la correspondencia diplomática francesa», Archivum Historicum S. I. [Roma], LIII, fasc. 105 (Ian.-Iun. 1984) 193-219. 
para el embajador francés, hay una utilización del bajo pueblo por gente de una especie más considerable, que había fomentado y sostenido la revuelta. Idea sobre la que vuelve d'Ossun al destacar que «sólo la canalla entró en el patio del palacio, y que los sacerdotes, monjes y gentes distinguidas entre la burguesía, que habían sostenido la sedición, no se hicieron visibles». Es decir, que la idea de complot subyace a lo largo de todo el informe.

Si de los protagonistas pasamos a las causas, queda patente ya desde el primer momento, tanto por las peticiones del pueblo como por las concesiones de Carlos III, que estamos en presencia de cuestiones políticas y socio-económicas íntimamente ligadas, en las que es difícil deslindar importancias o categorías, y que van desde el ¡Viva el rey, muera Esquilache, mueran los italianos!, hasta la petición de que se baje el precio del pan y del aceite, y que se quite la Junta de Abastos ${ }^{10}$, pasando por la exigencia de expulsión de los Guardias Walonas y la revocación de la prohibición de las capas largas y los sombreros gachos.

Como nota típicamente chauvinista no deja de ser significativo ese presunto protagonismo que se autoadjudica el embajador francés, amado del pueblo y de la nación, que no sólo no recibe insulto alguno, sino que a su paso por las calles escucha de los amotinados muchos ; Viva España y Francia!, y que poco menos se atribuye la pacificación de Madrid con la puesta en práctica de los consejos que se tomó la libertad de dar a Su Majestad Católica.

\section{Rebelión popular o fidelidad al rey}

El caso es que el tema de la revuelta de Madrid va a seguir ocupando el interés del embajador francés durante bastante tiempo ${ }^{11}$. Así en su despacho a Choiseul del 31 de marzo, escrito también desde Aranjuez, añadía al final el siguiente comentario: «Por lo demás, señor, aun-

10 Sobre este tema vid. García Monerris, M. ${ }^{a}$ del Carmen y Peset, José Luis, «Los gremios menores y el abastecimiento de Madrid durante la Ilustración», Moneda y Crédito, 140 (Marzo 1977) 67-97.

11 A título de ejemplo de lo que este tipo de fuentes pueden aportar incluyo a continuación una selección de los despachos remitidos por el embajador en las primeras semanas que siguieron a los sucesos de Madrid. 
que aparentemente el buen orden y la tranquilidad se hayan totalmente restablecidos en Madrid, que la Corte sea numerosa aquí, y que el Rey de España y su ministro no dejan apercibir ninguna alteración, sin embargo están muy ocupados con las medidas a tomar a raíz del singular y peligroso acontecimiento que acaban de experimentar, para poder todavía tratar otros asuntos en estas circunstancias». Y todavía añadiría: «La ciudad de Toledo, señor, ha ofrecido al rey de España por sus diputados la vida y los bienes de sus habitantes y presentado una suma de 300.000 reales; el capítulo ha hecho lo mismo y presentando una suma de 360.000 reales. Parece que este ejemplo será seguido por todas las ciudades de España; varias han escrito ya sobre el mismo tema y enviado sus diputados» ${ }^{12}$.

Una semana más tarde —el 7 de abril- volvía el embajador francés a ocuparse del tema con una visión excesivamente optimista que los acontecimientos de provincias muy pronto le harían rectificar:

Reina en Madrid, señor, una gran tranquilidad, y el fuego de la sedición no se ha comunicado a ninguna otra ciudad del reino; al contrario, algunas de las principales han asegurado a Su Majestad Católica su fidelidad y su entera entrega a su servicio. La oposición era contra el marqués de Esquilache, y su salida ha calmado los espíritus. Las tropas que marchaban hacia la capital han recibido la orden de detenerse; y parece que hasta el presente el rey de España prefiere el partido de la clemencia. Sin embargo no dudo, señor, que este monarca ordenará hacer secretamente la investigación de los autores de un atentado que ha dañado tan escandalosamente la autoridad real, y que castigará a los que descubra. Queda por saber si Su Majestad Católica volverá a Madrid, y cuándo regresará. Es cierto que se van a tomar medidas eficaces para ponerse al abrigo de un segundo suceso semejante. El primero no habría llegado si hubiera habido en Madrid un buen sistema de policía, porque el Gobierno, advertido a tiempo de la fermentación del pueblo, habría prevenido fácilmente los efectos. La advertencia ha sido demasiado fuerte. Pero hay motivos para creer que de un gran mal resultará un bien. Quizás pensáis, señor, que el objetivo más importante en las circunstancias presentes seria vengar la injuria hecha al soberano. Pero es preciso saber antes de decidir cuál es la disposición general de la nación, y si el rey de España podría contar con la fidelidad de sus tropas nacionales. Presumo que este Príncipe y sus ministros estarán informados sobre el particular. Sin embargo, señor, oigo de personas de todos los rangos y estado decir unánimemente que el Rey de España es amado y respetado por sus súbditos y que le han dado una prueba de fidelidad obligándole a despedir a un Ministro que destruía y arruinaba su reino; que la forma de hacerlo quizá sea criticable, pero que desgraciadamente ninguna otra lo habría conseguido. Finalmente, les oigo decir que en esta ocasión el pueblo se rebeló por un exceso de amor y fideli-

12 A. D.P. 545, fols, 240-244. Aranjuez, 31 marzo 1766. Ossun a Choiseul. 
dad. Creeréis fácilmente, señor, que es imposible que un francés sea persuadido de la solidez de este razonamiento. Pero debo callarme tanto más que no se me ha pedido mi opinión ${ }^{13}$.

No cabe duda de que las reflexiones del embajador francés son interesantes y aportan puntos de vista y matizaciones que nos permiten acercarnos a la complejidad de una situación en la que se intentaba tranformar la rebelión popular en acto de fidelidad y amor al rey.

\section{Grimaldi y el Consejo de Estado}

Pero apenas tres días más tarde, el 10 de abril, y en carta cifrada, expedía Ossun un largo despacho en el que se captan nuevos aspectos del problema, sobre todo por las críticas a Grimaldi y en especial ante la noticia de los graves sucesos ocurridos en Zaragoza:

Todo está físicamente tranquilo y dentro del orden normal en Madrid, pero queda inquietud en los espíritus, quizás por el temor de un castigo, quizás también por los puntos de vista personales de algunos particulares. Aquí llueven cartas anónimas al rey y a sus ministros. Unas son insolentes o llenas de una crítica amarga sobre la mala administración. Otras no tienen sentido común; otras, en fin, están bien razonadas. El marqués de Grimaldi es personalmente atacado y maltratado por esta vía despreciable, y se le ha llegado a escribir que, si no dejaba el ministerio, el fusil que debía matarle estaba ya cargado, y esto por la única razón de que es extranjero, pues no hay, por lo demás, nada que imputarle, y es, en general, bastante amado y estimado. Le creo afectado por estas amenazas, pero espero que acabará por asegurarse, y lo juzgo por el partido que ha tomado de persuadir al rey de España a tener un Consejo de Estado, compuesto de los Secretarios de Estado, del duque de Alba, del Sr. de Fuentes, del duque de Soto Mayor y del Sr. Massones, su hermano. El motivo ha sido la revuelta que ha tenido lugar en Zaragoza el 6 de este mes, en la que el bajo pueblo ha atacado la casa del Intendente y la de tres o cuatro particulares con el pretexto que hacían juntos monopolios con el artículo de granos y pan. La canalla ha saqueado estas cuatro o cinco casas, e incluso las ha incendiado. Los propietarios han tenido la dicha de salvarse. En estas circunstancias la nobleza, el capítulo y los burgueses han tomado las armas y han rogado al marqués de Castelar ${ }^{14}$, que había reunido la guarnición, que no se mezclara en este asunto; ellos han caído sobre los amotinados y han matado un número considerable, y finalmente les

13 A. D. P. 545, fols. 257-9. Aranjuez, 7 de abril 1766. Ossun a Choiseul. Todavía añade el despacho una noticia relativa al nombramiento como Secretario de Estado para la Guerra a D. Juan Gregorio de Muniain, Teniente General de sus ejércitos que mandaba en Extremadura, y que es calificado así: «Pasa por un hombre instruido en su oficio, activo y capaz; se le espera de aquí a pocos días».

Capitán General de Aragón. 
han expulsado a todos de la ciudad ${ }^{15}$. Es así, señor, como naturalmente habría tenido que comportarse Madrid, donde la seguridad que la parte sana de los habitantes ha mostrado durante el tumulto prueba bastante claramente que allí había un complot unánimemente formado para expulsar al marqués de Esquilache. Sea lo que sea, señor, el Consejo de Estado se ha reunido muy secretamente a las nueve de la tarde del día ocho. El rey de España ha hecho decir a estos señores que él no asistiría esta vez, pero que esperaría sin acostarse hasta ser informado del resultado de sus deliberaciones. Sé positivamente que las revueltas de Madrid y Zaragoza han sido los únicos temas que se han tratado en esta asamblea. También sé que el rey de España ha aprobado totalmente lo que el Consejo ha propuesto a este respecto. Pero ignoro lo que ha sido resuelto. Tengo motivos de presumir que han sido preferidos los medios suaves. Por lo demás, señor, es fácil constatar que el marqués de Grimaldi ha intentado callarse adulando el amor propio de los Consejeros de Estado, y particularmente del duque de Alba. Este ministro, sin duda, había considerado primero que los cuatro colegas, siendo españoles, se unirían y tomarían una influencia preponderante en los asuntos. Segundo, que si los asuntos continuaban discutiéndose en un Consejo, los consejeros de Estado se pondrían de su lado por reconocimiento y para jugar un papel más adulador. Tercero, finalmente, que no sería responsable ante el público del partido que Su Majestad Católica tomara definitivamente en las circunstancias presentes, de suerte que, aunque sea contrario a los principios ordinarios de los ministros españoles que haya un Consejo de Estado, me parece que el marqués de Grimaldi ha pensado acertadamente y en esta ocasión se ha conducido muy diestramente. Queda por saber si este Consejo continuará reuniéndose y cuánto durará este nuevo arreglo. Os suplico, señor, no comuniquéis mis reflexiones al Sr. de Magallón ${ }^{16}$, pues informaría con toda seguridad a su superior, lo que podría causarme problemas. Por otra parte, las personas que han tenido la amistad y confianza de informarme podrían encontrarse comprometidas ${ }^{17}$.

15 El abate Beliardi informaba al duque de Praslin, el 14 de abril de 1766, diciendo que «el bajo pueblo de Zaragoza, habiéndose amotinado, ha cometido desórdenes escandalosos, poniendo fuego a la casa del Intendente y a las de tres o cuatro personas empleadas en la finanza. Pero el clero, la nobleza y las gentes sensatas de la ciudad, habiendo tomado las armas han batido a la canalla, la han expulsado y puesto fuera de la ciudad. Estos detalles han agradado mucho a S. M.C., que ha podido reconocer en esta ocasión la fidelidad de su pueblo y el carácter que siempre le ha distinguido por su adhesión al soberano y a la seguridad legítima». A. D. P. 545, fols. 285-286. Sobre esta cuestión vid. Ferrer Benimeli, J. A., «D. Ramón Pignatelli y el motín de Esquilache. Una nueva versión del motín de Zaragoza», en Actas del I Symposium sobre la Ilustración Aragonesa, Zaragoza, D. G. A., 1986, donde se reproduce la amplia y detallada Relación de lo ocurrido en Zaragoza escrita por el hermano del conde de Fuentes, el canónigo Ramón Pignatelli, y que fue enviada a París por el embajador francés.

16 Secretario de la embajada española en París, cuyo superior y embajador era precisamente el conde de Fuentes que se encontraba esos días en Madrid.

17 A. D. P. 545, fols, 264-271. Aranjuez, 10 de abril 1766. Ossun a Choiseul [en cifra]. 


\section{Protagonismo francés}

Como se puede apreciar, la situación política de Grimaldi ocupa el centro del largo informe del embajador, quien admite, tras la revuelta de Zaragoza, la gravedad de la situación en España y la existencia de un complot formado para expulsar al marqués de Esquilache. Al menos, de momento, no insiste demasiado en otras connotaciones sociales que de hecho existían. También resulta interesante la interpretación que el francés hace de la utilización coyuntural de un Consejo de Estado ${ }^{18}$ dentro de un velado enfrentamiento del duque de Alba ante la política de Grimaldi.

Pero todavía tiene el despacho una parte final en la que el protagonismo francés se pone nuevamente de manifiesto ante un rumor al que la historiografía posterior no ha prestado mayor atención, y que hay que enmarcar en el contexto de xenofobia manifestada en Madrid, especialmente contra italianos y walones:

He observado, seffor, con mucha satisfacción, en este tiempo de disturbios y licencia, que los españoles no sólo no guardaban rencor a los franceses, sino que incluso los miraban como sus hermanos naturales y necesarios. $\mathrm{Y}$ se ha extendido en el público que somos el abate Beliardi ${ }^{19}$ y yo quienes hemos trabajado secretamente de acuerdo con el marqués de Grimaldi para hacer expulsar al marqués de Esquilache. Esta opinión absurda -prosigue el embajador - ha tomado mucho crédito, pero, como ya se le he dicho al abate, los que la han imaginado y verosímilmente divulgado con mala intención han fallado su objetivo, puesto que de un lado el rey de España está perfectamente informado de lo contrario, y de otro es hacernos un mérito ante los ojos de la nación española ${ }^{20}$.

El siguiente despacho está dedicado al conde de Aranda y su nombramiento como Presidente del Consejo de Castilla, y lleva la fecha del 14 de abril:

El rey de España, señor, ha juzgado conveniente nombrar al conde de Aranda Presidente del Consejo de Castilla, y darle al mismo tiempo el mando general de las tropas de Madrid y Castilla la Nueva, sin exceptuar las de su casa. El público ha aprobado mucho esta elección, y piensa que el conde

Que tal vez podría considerarse como un antecedente o germen de los futuros Consejos de Ministros.

Hombre clave de la diplomacia francesa en Madrid.

Vid. nota 17. 
de Aranda es capaz de llevar bien las importantes funciones de este eminente empleo que le hace jefe de todos los tribunales. Hay motivos para esperar, señor, que este señor restablecerá pronto el espíritu de tranquilidad y de sumisión en la capital, tanto más que vienen tropas para sostener sus operaciones, si las circunstancias lo exigen. El obispo de Cartagena, señor, que ha sido agradecido [por sus servicios], sólo tenía el título de Gobernador, y era amovible según la voluntad de la Corte. La situación de un Presidente es diferente puesto que para destituirle es preciso hacer su proceso y que sea juzgado digno de muerte. Aparentemente por esta consideración, y a causa de que el Presidente de Castilla tiene el honor de conferenciar una vez a la semana privadamente con el rey su dueño, es por lo que hacía mucho tiempo que se tenía cuidado en no nombrar un gran señor. Al mismo tiempo era casi de regla nombrar para ese cargo a un obispo, y esta circunstancia era consoladora para el clero de España y para la Corte de Roma ${ }^{21}$. También presumo que la idea de contener la ambición de los Grandes entraba en gran medida en el antiguo arreglo. Sea de ello lo que sea, señor, el rey de España y su ministerio han sido, sin duda, llevados por las circunstancias a pensar de forma diferente ${ }^{22}$.

Tras estas reflexiones, todavía añade el embajador francés una información relativa a la actitud de los reyes de Portugal ante los amotinados españoles:

Hace tres días llegó, señor, un expreso de Lisboa que ha traído a Su Majestad Católica cartas del rey y la reina de Portugal, en las que estos príncipes testimonian el desagrado que les ha causado lo ocurrido en Madrid, y aseguran que si alguno de los culpables buscara asilo en sus estados no sería recibido. Estas cartas contienen también los ofrecimientos más amables. Me ha parecido, señor, que Su Majestad Católica estaba extremadamente sensible a esta atención, y me ha hecho el honor de decirme que había insertado en la respuesta que había hecho personalmente a la reina su hermana, que el rey de Portugal podía contar con su reconocimiento y con una perfecta reciprocidad de buenos procedimientos por su parte, a pesar de los rumores que se habían difundido sobre un objeto en el cual no había ciertamente pensado nunca, es decir de atacar a Portugal ${ }^{23}$.

Por su parte, el número dos de la diplomacia francesa en España, el abate Beliardi, escribía por esas mismas fechas al duque de Praslin ${ }^{24}$, desde Aranjuez, la noticia de la llegada del conde de Aranda desde su

21 Obsérvese la matización diplomática que no habla de la Santa Sede sino de la Corte de Roma, haciendo la distinción tradicional en la época de los dos poderes, el espiritual y el temporal.

22 A.D.P. 545, fols. 281-284. Aranjuez, 14 de abril 1766. Ossun a Choiseul.

23

24

Praslin (Gabriel de Choiseul, duque de), oficial y diplomático francés, ministro de la marina de 1766 a 1770, nacido en París (1712-1785). Preparó la revancha marítima contra Inglaterra. 
gobierno de Valencia, y de la reunión de los Secretarios y Consejeros de Estado a la que había asistido el conde de Aranda, y en la que habían tratado «los medios de encaminar al pueblo de Madrid a su deber de evitar que su ejemplo incitara a hacer otro tanto a las grandes ciudades de España». Nada más concluir la reunión que había tenido lugar «el último viernes», el conde de Aranda partió de Aranjuez «a media noche para dirigirse a Madrid». $Y$ añade:

Llevaba consigo una lettre de cachet para el obispo de Cartagena, Gobernador del Consejo de Castilla, por la cual Su Majestad Católica le hacía saber que, las circunstancias actuales habiéndole hecho juzgar oportuno nombrar al conde de Aranda Presidente del Consejo de Castilla, podía retirarse sin tardanza de Madrid y volver a su diócesis. Esta carta le fue entregada ayer a las seis de la mañana y a las siete este primer Magistrado del Reino estaba ya fuera de Madrid. El conde de Aranda tomó posesión de la Presidencia del Consejo a las ocho. Su Majestad Católica le ha concedido al mismo tiempo el mando militar de toda la Castilla la Nueva, lo que lo convierte en un cargo del que no ha habido jamás ejemplo. Parece que este arreglo ha sido bien recibido en la capital, donde se han dado toda clase de aclamaciones ${ }^{25}$.

\section{Pasquines contra Grimaldi}

La impresión de aceptación y buen recibimiento del conde de Aranda es compartida también por el embajador d'Ossun apenas tres días después, en su despacho habitual con el jefe de la diplomacia francesa, Choiseul:

Parece que el nombramiento del conde de Aranda como Presidente del Consejo de Castilla es muy agradable a toda la nación española. Su presencia, sus talentos y sus cuidados no dejarán de restablecer en poco tiempo la tranquilidad en Madrid, fortaleciendo allí el respeto y la observancia debidos al soberano; y de poner en vigor un sistema de policía capaz de prevenir desórdenes semejantes al que acaba de experimentarse. Parece finalmente, señor, que se puede presumir que de un gran mal nacerá un gran bien. No obstante, como los carteles, pasquinadas y cartas anónimas no han cesado todavía totalmente por parte de los habitantes de Madrid, y que aquí es natural deducir de ello que personas por encima de la hez del pueblo han fomentado y quizás todavía fomentan el espíritu de sedición, se ha juzgado a propósito hacer acercar tropas. Varios regimientos están en marcha hacia la capital de suerte que hasta su llegada no se podrá ver claro ${ }^{26}$.

25 A.D.P. 545, fols. 285-286. Aranjuez, 14 de abril 1766. Beliardi a Praslin.

26 A.D.P. 545, fols. 296-299. Aranjuez, 17 de abril 1766. Ossun a Choiseul. 
Tras esta nueva alusión al complot poco menos que nobiliario, y en todo caso fomentado por personas por encima de la hez del pueblo, el embajador se ocupa otra vez de Grimaldi:

El marqués de Grimaldi, señor, ha sido maltratado en cartas anónimas, sin otro motivo que el que los españoles no quieren un extranjero en el ministerio. En efecto, ¿qué puede reprocharse a este ministro cuyos puntos de vista y operaciones tienden únicamente al bien público, y que no ha cesado de manifestar los sentimientos naturales de un hombre de su nacimiento y de su probidad? No obstante, sea que esto venga del público, sea que alguna cábala particular quiera aprovechar la circunstancia ${ }^{27}$, es cierto que se busca disgustarle e incluso alarmarle. Ignoro, señor, el efecto que las contradiciones tan poco merecidas han podido hacer en el espíritu y opiniones del marqués de Grimaldi, porque no es en modo alguno abierto conmigo, ni con nadie que yo sepa; pero observaría que si llegara a hastiarse de su cargo, sería muy importante para el mantenimiento de la unión formada entre las dos coronas que su sucesor tuviera principios favorables a este sistema ${ }^{28}$.

\section{Portugal y los artesanos de Barcelona}

De los elogios de Aranda y de la preocupación por una posible sústitución de Grimaldi que pondría en peligro su política franco-española, el embajador pasa a ocuparse nuevamente de la actitud del rey de Portugal ante lo que sucedía en España:

El rey de Portugal, señor, ha hecho hacer nuevas protestas de amistad y de servicio a Su Majestad Católica por medio de su embajador, y ha asegurado bajo su palabra de honor que si el rey de España juzgaba a propósito llamar cerca de él a las tropas empleadas en guardar las fronteras respectivas, que Su Majestad Fidelísima haría detener a todos los que entraran en sus Estados sin pasaportes de la Corte de España ${ }^{29}$.

Finalmente concluye este largo despacho con una referencia a Zaragoza:

La sedición, señor, que hubo en Zaragoza ha terminado con el castigo de los principales jefes de la revuelta. Ocho han sido ahorcados; algunos otros azotados públicamete y otros enviados a galeras; y el resto de España está sometida y tranquila ${ }^{30}$.

27 Obsérvese la insistencia o creencia complotista de Ossun.

28 A. D.P. 545, fols. 296-299. Aranjuez, 17 de abril 1766. Ossun a Choiseul.

Ibídem.

30 Ibídem. 
Los archivos del Quai d'Orsay conservan, siguiendo un orden cronológico, el Bando impreso de los gremios de artesanos y menestrales de Barcelona, del 20 de abril de 1766, que lógicamente no pudo ser enviado en el despacho que desde Aranjuez remitió Ossun el día siguiente. Pero en cualquier caso es una pieza más dentro de la campaña general de pacificación. Dicho Bando decía así:

Los Colegios y los Gremios de Artesanos y Menestrales de la presente Ciudad, con permiso del Excelentísimo Señor Marqués de la Mina, Capitán General del Exercito y Principado de Cataluña, etc.

Deseando continuar las pruebas de amor y fidelidad que justamente mantienen al Rey Nuestro Señor, y a fin de que no se turbe la Quietud Pública, ni se malquiste su honrado proceder por algunas precauciones precisas a que han obligado, sin duda, pocos naturales o forasteros mal entretenidos y de perniciosas intenciones, que de algunos días a esta parte han fijado clandestinamente Pasquines sediciosos con injuria de muchas Personas autorizadas, hacen saber que darán mil pesos de gratificación a qualquiera que descubriere el Autor o Autores de semejantes Papeles o de parte de ellos con prueba legítima y suficiente, en la inteligencia de que jamás se descubrirá su nombre, ni se darán señas por donde pueda inferirse, y que si fuese cómplice se le perdonará su delito.

El dinero se depositará en los doce Diputados que últimamente han nombrado, para entender en las presentes ocurrencias, los Colegios y Gremios de la presente Ciudad. Barcelona, 20 de abril de 1766.

Certifico, como Secretario de la Capitania General de este Exército y Principado, que los Gremios tienen facultad y licencia de su Excelencia para la publicación de este Papel y de lo ofrecido en él -Don Manuel de Vadillo» ${ }^{31}$.

\section{De nuevo el conde de Aranda}

En el despacho fechado un día después de este Bando, el embajador vuelve a ocuparse del conde de Aranda y de sus primeras medidas:

El conde de Aranda, señor, se conduce lo mejor posible en el importante empleo que le ha sido confiado, y presumo que antes de un mes todas las cosas habrán sido puestas en orden. El marqués de la Ensenada, señor, ha dejado la capital el 18 del corriente ${ }^{32}$, con orden de retirarse a una ciudad de Castilla la Vieja, que se llama Medina del Campo. Se me ha asegurado que se le permitirá fijar su residencia en Valladolid. Ignoro el verdadero motivo de su exilio ${ }^{33}$, pero sea el que fuere, en las circunstancias presentes ha contribuido mucho a aumentar el malestar ${ }^{34}$.

31 A. D. P. 545, fol. 309.

32 Es decir, a los cuatro días del nombramiento del conde de Aranda.

33 Vid, nota 9.

34 A.D.P. 545, fol. 313. Aranjuez 21 de abril 1766. Ossun a Choiseul. 
Y como contrapunto de lo anterior, y en ese afán un tanto contradictorio por dar la sensación de paz y tranquilidad, añade el embajador:

Todo está en Madrid, señor, tranquilo, y en obediencia, y Su Majestad Católica ha tenido la satisfacción de recibir nuevos testimonios de sumisión, fidelidad y adhesión de todas las otras ciudades del Reino ${ }^{35}$, excepto de la de Zaragoza, si bien se puede decir que la sedición que tuvo sirvió para conocer mejor la fidelidad de sus principales habitantes ${ }^{36}$.

Sobre estos dos mismos puntos, el conde de Aranda y la presunta tranquilidad general, se ocupa también el encargado de la embajada española en París, Magallón, quien al remitir a Choiseul dos cartas recibidas por el correo ordinario, de la Princesa de Asturias, dirigidas al rey y la reina franceses, comenta lo siguiente:

Las cartas de Madrid mandan el nombramiento del señor de Aranda para el empleo de Presidente del Consejo. Esta plaza, que no ha sido cubierta desde el siglo pasado, es la de mayor autoridad en todo el reino. La justicia, la policía, y todo el gobierno interior depende de ella. A lo que se añade en el caso del señor de Aranda el gobierno militar de Madrid y el mando de las tropas de Castilla, por medio de lo cual tendrá la autoridad y la fuerza ${ }^{37}$.

Respecto al estado general de la nación añadía, un tanto escéptico:

Madrid parece completamente tranquilo; la tormenta de Zaragoza parece también calmada, pero no sé si estas apariencias deben poner el abrigo de toda inquietud ${ }^{38}$.

\section{La tranquilidad de Madrid}

En esta misma línea y como si se tratara de un leit-motiv, el 28 de abril volvía el embajador francés en Madrid sobre la misma cuestión:

Reina, señor, la mayor tranquilidad en Madrid y en toda España. Pero queda todavía por vengar la injuria hecha a la autoridad real, y me parece que se camina muy lentamente. No obstante, Su Majestad Católica parece

Seguramente y como pueba de lo dicho, el embajador incorporó el Bando de Barcelona inserto más arriba.

Ibídem. El despacho concluye con la noticia de la incorporación del rey a su ocupación favorita, la caza; para lo que se había ausentado del miércoles al viernes a catorce leguas de Aranjuez.

37 A.D.P. 545, fol. 325. París, 26 abril 1766. Magallón a Choiseul. 
ser consciente de las consecuencias que de ello se puedan derivar tanto en el interior como en el exterior ${ }^{39}$.

Efectivamente, en el exterior, y Choiseul el primero de ellos, dudaban bastante de esa aparente tranquilidad. En este sentido la correspondencia diplomática mantenida durante el mes de mayo entre Aranjuez y París resulta especialmente interesante. Ya el 9 de mayo escribía así el embajador francés:

No estoy sorprendido, señor, de que cartas particualres hayan anunciado que la fermentación no estaba todavía tan adormecida en Madrid como yo os lo había indicado. Los particulares se explican siguiendo prevenciones o puntos de vista que les son personales, o bien fundan su juicio sobre apariencias que no deciden en modo alguno de la disposición general de los espíritus. Por lo demás, señor, podéis considerar como cierto que la ciudad de Madrid está totalmente tranquila, y que incluso reina en ella al presente una policía muy exacta; por otra parte se han tomado medidas suficientes a fin de que ya jamás pueda suceder un acontecimiento tan indecente como el que se ha experimentado, y que sin duda exigirá el castigo más ejemplar, pero que no sé mucho en qué consistirá ${ }^{40}$.

\section{El Consejo de Estado y las Malvinas}

A continuación se ocupa de los nuevos ministros de Guerra y Marina ${ }^{41}$ :

Los dos nuevos ministros, señor, son capaces de hacerlo bien y parecen tener un gran deseo. El de la guerra conoce el mal estado en el que está el ejército de España; razona muy justamente sobre este objeto y asegura que va a trabajar eficazmente en ponerlo en regla. Respecto al de Marina, estoy inquieto creyendo que el magistrado Arriaga juzgue conveniente no cambiar nada respecto a su conducta y sistema ordinario. No obstante, puede suceder que este ministro se vea forzado por una serie de resoluciones del comité que se ha establecido para examinar los asuntos que afectan al Estado, sea en el interior, sea en el exterior. Este comité, señor, está compuesto de los cuatro secretarios de Estado que están en la Corte, a saber, el duque de Alba, el Sr. Massones y el duque que de Sotomayor su hermano, el conde de Fuentes y el Sr. Wall ${ }^{42}$.

39 A. D. P. 545, fol. 337. Aranjuez, 28 de abril 1766. Ossun a Choiseul.

A.D.P. 545, fols, 353-357. Aranjuez, 9 de mayo 1766. Ossun a Choiseul.

Sobre el nombramiento de Juan Gregorio de Muniain como Secretario de Estado para la Guerra, vid. nota 13.

Vid. nota 40. Como se aprecia, en lugar de cuatro Secretarios cita cinco, al incluir entre ellos al Consejero de Estado y embajador en París, conde de Fuentes, que en esas fechas se encontraba en Madrid. 
Tras esta alusión a la nueva forma de gobierno adoptada por la Corte española y que, como hemos visto maś arriba ${ }^{43}$, prefigura en cierto sentido lo que más tarde serían los Consejos de Ministros, informa Ossun de la primera iniciativa de dicho comité, referente precisamente a las islas Malvinas:

Este comité, señor, es el que acaba de decidir que el Sr. de Bougainville abandone el establecimiento que había formado en las islas Malvinas, y que España ocupe inmediatamente ese Puesto importante para la comodidad y la seguridad de la navegación en el mar del sur. Al mismo tiempo se ha decidido que la Corte de Madrid reembolse los gastos legítimamente hechos en esta ocasión por el Sr. de Bougainville; y el marqués de Grimaldi me ha dicho que el Sr. de Magallón sería encargado de arreglar este tema con los ministros del rey; de suerte que el Sr. de Bougainville se propone quitarnos de aquí a cinco o diez días ${ }^{44}$.

Como corolario final, el embajador vuelve a analizar el cambio de la forma de gobierno experimentada a raíz de los motines de Madrid y Zaragoza:

Podéis inferir, señor, dos cosas de lo que acabo de exponer. La primera es que el método de tratar los asuntos en esta Corte ha cambiado, y consiste en que al presente son examinados, sean de la materia que sean, por un comité cuya opinión es elevada a Su Majestad Católica por el secretario del Departamento del que depende el asunto tratado. La segunda es que la pluralidad de votos influirá verosímilmente en el futuro sobre las decisiones, en lugar de que hasta ahora era de gran peso el parecer del Secretario de Estado que trabajaba con el rey, su dueño. Por lo demás, parece que el marqués de Grimaldi ha alcanzado una estima y confianza muy particulares por parte del duque de Alba y de los Srs. Massones y Sotomayor, quienes se manifiestan abierta y muy favorablemente sobre la necesidad de mantener el sistema establecido por el Pacto de Familia ${ }^{45}$.

\section{Los motines y la pobreza de España}

La misiva anterior se cruzó con la que el propio Choiseul enviaba a Ossun desde Versailles, y que lleva la fecha del 6 de mayo, en la que volvía a poner en duda la pacificación del reino español y en la que abogaba por medidas de rigor más severo:

\footnotetext{
43 Vid. nota 18.

44 Vid. nota 40.

45 Ibidem.
} 
Tengo la impresión de que en Aranjuez cuentan quizás demasiado los testimonios de sumisión y de fidelidad que Su Majestad Católica recibe de la mayor parte de las ciudades de su reino. Sin embargo, nosotros tenemos motivos para creer que el fuego todavía no se ha apagado en todas las provincias de España, y sabemos muy positivamente que recientemente ha habido revueltas populares en la frontera, cerca de Bayona, y especialmente en Fuenterrabía ${ }^{46}$. Ciertamente sólo las medidas del rigor más severo pueden sujetar al populacho y hacerlo entrar en los deberes de la obediencia más total a la autoridad del Gobierno. Pues algunos castigos pasajeros sólo encubrirán el mal, y no se puede reparar sólidamente mientras no se llegue a descubrir los instigadores y ejecutores de las revueltas de Madrid y Zaragoza ${ }^{47}$.

Como se observará, Choiseul, desde París, daba la impresión de estar, en cierto sentido, mejor informado que su embajador, recluido en Aranjuez y sometido a una información quizá excesivamente preocupada por quitar todo alarmismo. Y para paliar esta impresión y justificar sus anteriores informes, se vio obligado Ossun a enviarle el 12 de mayo un largo despacho cifrado en el que se encuentran las claves, por así decir, de los motines contra Esquilache, y que esta vez se entroncan ya, al menos en provincias, con los motines de subsistencias:

Podéis, señor, dar crédito a la relación que he tenido el honor de enviaros sobre la revuelta de Zaragoza ${ }^{48}$, y creer que la fidelidad y rigor con los que se ha comportado la parte más sana de los habitantes de la ciudad han establecido allí sólidamente el espíritu de sumisión y de tranqulidad. Ha habido algunos movimientos en otras cuatro o cinco ciudades o aldeas de España con ocasión de la carestía del pan ${ }^{49}$, pero como eran provocados por el bajo pueblo y los principales habitantes se han apresurado a apaciguar la revuelta, estas ligeras sacudidas no han tenido ninguna consecuencia y todo está general y enteramente pacificado. Vuestras reflexiones, señor, son muy justas con relación a los grandes inconvenientes que pueden resultar de la extrema pobreza del populacho español; no obstante no todas las provincias del reino están en la misma situación. Los pueblos son laboriosos, activos e industriosos en Galicia, Vizcaya, Navarra, Cataluña y el reino de Aragón; sólo en las Andalucías y las Castillas, sobre todo la Nueva, la pobreza del bajo pueble es extrema, y esto viene principalmente de que la mayor parte de las tierras pertenecen directamente al rey, a los grandes señores y al clero secular y re-

46 Sobre este tema vid. Otazu, A. de, «La represión de la matxinada de 1766 , en La burguesía revolucionaria vasca a fines del siglo XVIII, San Sebastián, Ed. Txertoa, 1982, y Corona, C., Los motines de 1766 en las provincias vascas. La Machinada, Zaragoza, Universidad, 1985.

47 A. D. P. 545, fol. 363. Versalles, 6 mayo 1766. Choiseul a Ossun.

48 A. D. P. 545, fols. 272-280. Vid. nota 15.

49 En realidad, aquí el marqués de Ossun parece ser que no estaba correctamente informado, pues no fueron cuatro o cinco, sino casi un centenar los pueblos y ciudades que experimentaron motines por esas fechas. 
gular. Estos señores descuidan la agricultura; el clero, y especialmente los frailes, la explotan ellos mismos, y los campesinos que no tienen tierras en propiedad solamente pueden subsistir con el trabajo de sus manos o pidiendo limosna, y esto último es lo que de ordinario prefieren. Sería fácil, señor, remediar este mal dando las tierras al pueblo con un canon en granos proporcional a la fertilidad del suelo. Los propietarios no perderían con ello, al contrario; y el Estado obtendría una gran ventaja. Otra fuente de pobreza y de ociosidad del pueblo deriva de los derechos considerables que son impuestos sobre el consumo con el nombre de alcabalas y millones y rentas provinciales; derechos que suplen al tributo real que no existe en España ${ }^{50}$.

\section{La reforma del escusado y el complot de clero}

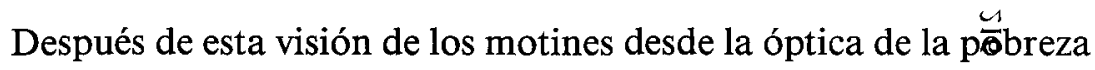
y sus causas en España, el embajador vuelve a su ya conocida tesis complotista en la que adjudica, en este caso, un importante papel al clero:

No creáis, señor, que el populacho español haya tomado el partido general de las revueltas. Estad seguro que sólo lo hizo en Madrid, y al presente se sabe bien que el pueblo fue sólo el instrumento de que los sacerdotes y frailes se han servido, bajo el manto de la religión y con la ayuda del fanatismo, ignorancia y superstición. Pero tampoco hay que creer, señor, que el espíritu de sedición sea general entre los sacerdotes y frailes; son personajes principales del clero los que han puesto un cierto número de sus subalternos en movimiento ${ }^{51}$.

A continuación el embajador francés explica el porqué de esa actitud del clero, que no era otro que la reforma del escusado llevada a cabo por el marqués de Esquilache, así como la cuestión del diezmo sobre las tierras de regadío:

He aquí el verdadero motivo de esta detestable intriga. La Corte de Ro$\mathrm{ma}^{52}$, señor, había acordado a Felipe II, con motivo de la guerra contra los moros, el derecho de percibir en cada parroquia el diezmo entero sobre las posesiones de los particulares. El clero rico de España se opuso entonces a esta concesión y Felipe II juzgó oportuno llegar a un arreglo con el clero mediante una suma de dos millones de reales, más o menos, que los obispos y capítulos se comprometían a pagarle anualmente, bien entendido que gozarían de la concesión apostólica en toda su extensión. El marqués de Esquilache llegó y dijo que el rey, su señor, ya no quería anticipar el escusado (es el nombre del derecho del que se trata) y que quería ponerlo en administra-

so A. D. P. 545, fols. 371-381. Aranjuez, 12 mayo 1766. Ossun a Choiseul [En cifra].

51 Ibídem.

Vid. nota 21 . 
ción. El clero hizo las más vivas representaciones y empleó todos los medios, grandes y pequeños, para parar este golpe, pero el marqués de Esquilache, ayudado del voto del confesor de Su Majestad Católica lo llevó a cabo; y este ministro había arrendado el escusado sobre la base de doce millones de reales por año; y además acababa de poner en vigor la pretensión de un nuevo impuesto basado en otra bula, cuando en uno de los reinados precedentes se planteó hacer canales de riego, por la que se concedió al Rey de España, que debía hacer el gasto, el diezmo de las tierras regadas que fueran nuevamente roturadas. Los canales proyectados sólo se realizaron en parte, y la mayoría de ellos ya ni existen; no obstante el marqués de Esquilache pretendía tener el derecho a recibir dicho impuesto no solamente de las tierras indicadas por la Bula de concesión, sino también de todas aquellas que habian sido roturadas en España desde la fecha de la Bula, e incluso sobre las que en el futuro fueran roturadas. Este ministro seguía este asunto con empeño, y existe la apariencia de que fue lo que les había hecho decidir a los autores de los desórdenes. Había incluso tratado de emplear la autoridad, pero de ello resultó una hidra de verificaciones y procesos, nombrándose una Junta para informar sobre el tema. Dudo mucho que actualmente el fisco haya desistido de su pretensión; queda el complemento del escusado. Ha sido preciso eliminar al marqués de Esquilache para poder esperar la anulación de las decisiones anteriores. $\mathrm{El}$ medio ha sido violento y criminal, pero este ministro era tan universalmente odiado que toda la nación ha aprobado bastante públicamente lo que ha decidido. De esta forma, señor, se han servido de la carestía del pan y de los comestibles, del bando contra las capas, para agitar al bajo pueblo; se le ha hecho romper las farolas para comenzar; por lo demás, no es fácil contener un populacho sublevado en los límites proyectados. No obstante la impunidad, la condescendencia y las causas de semejante suceso han impulsado a algunos particulares que no tenían seguramente nada que ver con el complot a escribir cartas anónimas, a divulgar pasquines y a desafiar al Gobierno. Se sabe que han salido de Madrid insinuaciones a varias ciudades de provincias para comprometerlas a imitar a la capital, pero felizmente no lo han conseguido ${ }^{53}$. Se asegura que el plan era elegir el momento en el que el rey de España haría la estación del jueves santo para coger al marqués de Esquilache, que debía acompañarle, pasearle por las calles sobre un asno, colgarlo a continuación en la plaza mayor, y venir inmediatamente a pedir a Su Majestad Católica lo que fuere. El rey de España quería conocer los verdaderos autores de la revuelta, y se le ha asegurado que el vil pueblo sólo había sido el agente, pero parece ser que los que podrían y deberían descubrir a estos autores no se prestan a los deseos del soberano, y que se contentan con establecer una buena policía y tomar medidas seguras para que no vuelva a suceder jamás en Madrid un escándalo semejante ${ }^{54}$.

53 Aquí nuevamente llama la atención el interés del embajador por quitar importancia a un hecho que había tenido ya múltiples repercusiones en provincias.

Vid. nota 50. 


\section{Aranda y la ayuda de Cataluña}

Este largo e interesante despacho cifrado del embajador Ossun concluye con una nueva alusión a la actitud de los españoles respecto a los franceses:

He observado, señor, en esta ocasión, que los españoles en general están de vuelta de la aversión que tenían hacia la nación francesa y que comienzan a mirarnos como sus aliados necesarios. Hablo en general, pues ciertamente había algunos particulares que manifestaban sentimientos contrarios ${ }^{55}$.

Las últimas palabras del embajador son para manifestar a su superior Choiseul que no respondería, ni siquiera en cifra, a algunos puntos de los dos últimos despachos ${ }^{56}$, y esperaría la próxima salida de Bougainville para hacerlo, ya que sabía de buenas tintas que «la vía de los despachos en cifra no era en modo alguno segura». Por otra parte añadía: «El conde de Fuentes ya se ha despedido y vos le veréis inmediatamente y os pondrá perfectamente al corriente de todo ${ }^{57}$.

El mismo 12 de mayo de 1766, pero en carta no cifrada, el embajador se ocupaba una vez más del conde de Aranda y de algunas otras revueltas acaecidas en cuatro o cinco ciudades españolas, así como de la reacción del rey y de Cataluña a este propósito:

El señor conde de Aranda cumple con la mayor distinción el importante cargo que le ha sido confiado, y ya ha establecido una excelente policía en Madrid. Reina en la ciudad mucha tranquilidad, así como en todo el resto del reino. Ha habido noticias de revueltas en cuatro o cinco ciudades de España, pero los comandantes o los magistrados las habían sofocado al punto y habían prometido un perdón general a imitación del que se había practicado en Madrid. Su Majestad Católica no ha juzgado a propósito confirmar estos perdones, y por el contrario acaba de ordenar que los culpables sean castigados según el rigor de las leyes. Se me asegura, señor, que muy pronto van a llegar aquí cuatro diputados del principado de Cataluña, que vienen a ofrecer al rey de España retirar, si lo juzga a propósito, todas las tropas 
que están en esta provincia para emplearlas allá donde sean necesarias, y que la provincia reclutaría y mantendría a sus expensas cuatro mil hombres para defenderse durante todo el tiempo que agrade al rey de España ${ }^{58}$.

Este documento se cruzaba en el camino con otro de Choiseul, fechado en Versailles el 13 de mayo de 1766, en el que se ocupaba precisamente del conde de Aranda:

Lo que me habéis dicho sobre los talentos y sobre el carácter del señor conde de Aranda me ha confirmado en la persuasión en la que ya estaba de que el señor Presidente del Consejo de Castilla justificaría por su celo y su éxito la señal de confianza que el Rey Católico ha juzgado a propósito darle ${ }^{59}$.

\section{Reflexiones finales}

Lógicamente la correspondencia entre Aranjuez y París continúa y lo hace con nuevas pistas y connotaciones claves para la comprensión del motín de Madrid, pues conforme pasaban los días las noticias y rumores aumentaban, pero exigencias editoriales nos obligan a detenernos hoy aquí.

En cualquier caso, y a pesar de su parcialidad temporal, ya que el período estudiado abarca solamente del 24 de marzo al 13 de mayo, es decir algo menos de dos meses de correspondencia diplomática, y a pesar de estar ésta circunscrita a un solo embajador con unos intereses políticos muy concretos, representados en gran medida en la defensa del Pacto de Familia bien visto por una de las «víctimas» del motín ${ }^{60}$, los despachos de Ossun nos proporcionan una serie de datos de gran interés en torno a lo sucedido en Madrid y en España en la primavera de 1766. Datos que van desde una nueva versión del motín contra Esquilache hasta las explicaciones político-económicas de por qué se había llegado a esa situación, pasando por unas reflexiones sobre los culpables del mismo que habían manejado al pueblo ${ }^{61}$ utilizándolo en in-

A.D.P. 545, fols. 383-385. Aranjuez, 12 mayo 1766. Ossun a Choiseul.

A. D. P. 545, fol. 391. Versailles, 13 mayo 1766. Choiseul a Ossun.

60 Grimaldi. De ahí la simpatía con que este ministro es mirado por Ossun, quien sale en su defensa frente a los ataques de pasquines y cartas anónimas.

61 No deja de ser llamativo el desprecio constante que el embajador hace del bajo pueblo al que otorga calificativos como el de vil canalla, hez y populacho. 
terés propio dentro de la clásica tesis complotista burguesa y clerical, en la que el embajador distingue claramente desde el primer momento entre autores y agentes.

$\mathrm{Si}$ a esto añadimos las reflexiones políticas en torno a personajes como el conde de Aranda, el duque de Alba, los ministros Grimaldi, Muniain y Arriaga, las repercusiones del motín en Portugal y Cataluña, la descripción de la pobreza en España y sus causas, la implantación del Consejo de Estado, etc. llegaremos a la conclusión de que, a pesar de su parcialidad, la lectura de la correspondencia diplomática sigue siendo una fuente de información todavía útil y válida. 